\title{
O barco ébrio / Le bateau ivre
}

Arthur Rimbaud

Como eu descesse por uns Rios impassíveis, Não mais me achei guiado pelos sirgadores: Peles-vermelhas, aos gritos, neles miraram, Pregando-os nus a uns postes multicores.

Não me importavam todos os carregamentos De trigos flamengos ou algodão inglês. Com meus sirgadores cessada a gritaria, Os Rios me deixaram ir onde queria.

Nos arrepios furiosos das marés,

Outro inverno, surdo tal cérebros infantes, Eu corri! E as Penínsulas desatadas Não sofreram tohu-bohus mais triunfantes.

Tempestade benzeu-me excitações marítimas. Mais ligeiro que rolha dancei sobre as ondas, Chamadas roladoras eternas de vítimas, Dez noites, sem chorar o asno olho dos faróis!

Doce aos infantes qual carne de maçãs ácidas, A água verde penetra meu casco píneo E manchas de vinhos azuis e vomitórios De mim dissipa, dispersando leme e âncora.

E, desde então, eu tomo banho no Poema do Mar, numa infusão de astros, pois lactado, Tragando azuis verdes, de onde, flotando lívido, Formoso, desce às vezes pênsil afogado;
Comme je descendais des Fleuves impassibles, Je ne me sentis plus guidé par les haleurs: Des Peaux-rouges criards les avaient pris pour cibles Les ayant cloués nus aux poteaux de couleurs.

J'étais insoucieux de tous les équipages,

Porteur de blés flamands ou de cotons anglais. Quand avec mes haleurs ont fini ces tapages Les Fleuves m'ont laissé descendre où je voulais.

Dans les clapotements furieux des marées, Moi, l'autre hiver, plus sourd que les cerveaux d'enfants, Je courus ! Et les Péninsules démarrées N'ont pas subi tohu-bohus plus triomphants.

La tempête a béni mes éveils maritimes. Plus léger qu'un bouchon j'ai dansé sur les flots Qu'on appelle rouleurs éternels de victimes, Dix nuits, sans regretter l'œil niais des falots !

Plus douce qu'aux enfants la chair des pommes sures, L'eau verte pénétra ma coque de sapin Et des taches de vins bleus et des vomissures Me lava, dispersant gouvernail et grappin.

Et dès lors, je me suis baigné dans le Poème De la Mer, infusé d'astres, et lactescent, Dévorant les azurs verts; où, flottaison blême Et ravie, un noyé pensif parfois descend;

* Fonte: RIMBAUD, Arthur. Poésies, Une saison en enfer, Illuminations. Préface de René Char. Édition établie par Louis Forestier. Paris: Poésie/Gallimard, 1973. Tradução de Carlos Eduardo Schmidt Capela; revisão de Fernando Scheibe. 
Onde, tingindo súbitos azuis, delírios, Ritmos lentos sob refulgências do alvor, Mais fortes que o álcool, vastos que nossas liras, Fermentam os roxos amargores do amor.

Conheço os céus cravados de raios, as trombas, Ressacas e correntes: sei do anoitecer, Da Alvorada exaltada tal bando de pombas, $\mathrm{Vi}$ às vezes o que o homem pensou ver!

Vi o sol baixo, manchado de horrores místicos, Iluminando coágulos violetas,

Parecendo atores de dramas bem antigos, Ondas rolando longe arrepios de alhetas!

Sonhei noite verde de neves ofuscantes, Beijo levando aos olhos mares com lerdeza, A circulação de umas seivas fecundantes, E o coro de ouro e azul dos fósforos cantores!

Segui, por plenos meses, como em vacarias Histéricas, a onda em assalto aos recifes, Sem pensar os pés luminosos das Marias Puxando pela fuça Oceanos bravios!

Abordei, é bom que se saiba, incríveis Flóridas Mesclando a flores olhos de linces em pele De homens! Arco-íris tensos como bridas Sob o horizonte dos mares, quais glaucas tropas!

Vi fermentar uns pântanos enormes, nassas Onde entre juncos putrefaz um Leviatã! Desbordamentos d'águas meio a calmarias, E lonjuras rumo a grotas cataratantes!

Geleiras, sóis prata, ondas nácar, céus brasa! Encalhes cruéis no fundo de golfos pardos Onde cobras gigantes sugadas de insetos Alentam, troncos torços, com negros perfumes!

Queria ter mostrado aos infantes dourados De onda azul, os peixes d'ouro, peixes cantantes.

- Espumas de flores me embalaram as derivas

E inefáveis ventos me alçaram por instantes.

Às vezes, mártir lasso de polos e zonas, O mar soluçava uma maré adoçada, Trazia flores sombrias, ventosas úmbrias, E eu restava, qual mulher ajoelhada...

Quase ilha, agitando nas bordas querelas E excrementos de aves malditas, de olhos loiros, Eu vogava, e por entre meus laços delgados Afogados incoavam dormir, recuados!

Ou eu, barco perdido em cabelos das ansas, Jogado pelo tufão num éter sem pássaro, Eu, de quem Monitores e veleiros de Hansas Não teriam salvo a carcaça ébria d'água,
Où, teignant tout à coup les bleuités, délires Et rhythmes lents sous les rutilements du jour, Plus fortes que l'alcool, plus vastes que nos lyres, Fermentent les rousseurs amères de l'amour !

Je sais les cieux crevant en éclairs, et les trombes Et les ressacs et les courants : je sais le soir, L'Aube exaltée ainsi qu'un peuple de colombes, Et j'ai vu quelquefois ce que l'homme a cru voir!

J'ai vu le soleil bas, taché d'horreurs mystiques, Illuminant de longs figements violets, Pareils à des acteurs de drames très antiques Les flots roulant au loin leurs frissons de volets!

J'ai rêvé la nuit verte aux neiges éblouies, Baiser montant aux yeux des mers avec lenteurs, La circulation des sèves inouies, Et l'éveil jaune et bleu des phosphores chanteurs !

J'ai suivi, des mois pleins, pareille aux vacheries Hystériques, la houle à l'assaut des récifs, Sans songer que les pieds lumineux des Maries Pussent forcer le mufle aux Océans poussifs !

J'ai heurté, savez-vous, d'incroyables Florides Mêlant aux fleurs des yeux de panthères à peaux D'hommes! Des arcs-en-ciel tendus comme des brides Sous l'horizon des mers, à de glauques troupeaux !

J'ai vu fermenter les marais énormes, nasses Où pourrit dans les joncs tout un Léviathan! Des écroulements d'eaux au milieu des bonaces, Et les lointains vers les gouffres cataractant !

Glaciers, soleils d'argent, flots nacreux, cieux de braises! Échouages hideux au fond des golfes bruns Où les serpents géants dévorés des punaises Choient, des arbres tordus, avec de noirs parfums!

J'aurais voulu montrer aux enfants ces dorades Du flot bleu, ces poissons d'or, ces poissons chantants. - Des écumes de fleurs ont bercé mes dérades Et d'ineffables vents m'ont ailé par instants.

Parfois, martyr lassé des pôles et des zones, La mer dont le sanglot faisait mon roulis doux Montait vers moi ses fleurs d'ombre aux ventouses jaunes Et je restais, ainsi qu'une femme à genoux...

Presque île, ballottant sur mes bords les querelles Et les fientes d'oiseaux clabaudeurs aux yeux blonds. Et je voguais, lorsqu'à travers mes liens frêles Des noyés descendaient dormir, à reculons !

Or moi, bateau perdu sous les cheveux des anses, Jeté par l'ouragan dans l'éther sans oiseau, Moi dont les Monitors et les voiliers des Hanses N'auraient pas repêché la carcasse ivre d'eau; 
Livre, fumoso, envolto em brumas violetas, Furava o céu enrubescido, como umbral Que oferta, geleia atraente aos bons poetas, Uns líquens de sol, umas corizas de azul;

Eu corria, tinto de lúnulas elétricas, Prancha louca, do lado de hipocampos negros, Quando aos golpes julhos faziam desabar Os céus dos ardentes funis do ultramar;

$\mathrm{Eu}$, tremendo ao eco ouvir, a cinquenta léguas, Do cio dos Behemots e Maelstroms compactos, Fiandeiro eterno de inércias azuladas, Lamento a Europa de velhos parapeitos!

Vi arquipélagos siderais! e umas ilhas Cujos céus se abrem em delírio ao navegador: - Nessas noites sem fundo dormes e te exilas, Um milhão de aves d'ouro, ó futuro Vigor?

Mas chorei demais! As Auroras são tocantes. Toda lua é atroz e todo sol amargo: Acre amor me encheu de torpores delirantes. Que minha quilha arrebente! Que eu vá a pique!

Se desejo uma água da Europa, é da poça Negra e fria onde, no ocaso embalsamado, Um infante agachado, tristemente, solta Um barco frágil tal borboleta de maio.

Não posso mais, banhado em seu langor, ó lâminas, Demover trilhas de cargueiros de algodões, Atravessar o orgulho de chamas e flâmulas, Nem nadar sob olhos horríveis dos pontões.
Libre, fumant, monté de brumes violettes, Moi qui trouais le ciel rougeoyant comme un mur Qui porte, confiture exquise aux bons poètes, Des lichens de soleil et des morves d'azur,

Qui courais, taché de lunules électriques, Planche folle, escorté des hippocampes noirs, Quand les juillets faisaient crouler à coups de triques Les cieux ultramarins aux ardents entonnoirs;

Moi qui tremblais, sentant geindre à cinquante lieues Le rut des Béhémots et les Maelstroms épais, Fileur éternel des immobilités bleues, Je regrette l'Europe aux anciens parapets !

J'ai vu des archipels sidéraux ! et des îles Dont les cieux délirants sont ouverts au vogueur: - Est-ce en ces nuits sans fonds que tu dors et t'exiles, Million d'oiseaux d'or, ô future Vigueur? -

Mais, vrai, j'ai trop pleuré ! Les Aubes sont navrantes. Toute lune est atroce et tout soleil amer:

L'âcre amour m'a gonflé de torpeurs enivrantes. Ô que ma quille éclate! Ô que j'aille à la mer !

Si je désire une eau d'Europe, c'est la flache Noire et froide où vers le crépuscule embaumé Un enfant accroupi plein de tristesse, lâche Un bateau frêle comme un papillon de mai.

Je ne puis plus, baigné de vos langueurs, ô lames, Enlever leur sillage aux porteurs de cotons, $\mathrm{Ni}$ traverser l'orgueil des drapeaux et des flammes, $\mathrm{Ni}$ nager sous les yeux horribles des pontons. 
